\title{
Between-course targeting of methotrexate exposure using pharmacokinetically guided dosage adjustments
}

\author{
Jennifer L. Pauley $\cdot$ John C. Panetta $\cdot$ Kristine R. Crews $\cdot$ Deqing Pei $\cdot$ Cheng Cheng $\cdot$ \\ John McCormick • Scott C. Howard • John T. Sandlund • Sima Jeha • Raul Ribeiro • \\ Jeffrey Rubnitz $\cdot$ Ching-Hon Pui $\cdot$ William E. Evans $\cdot$ Mary V. Relling
}

Received: 30 January 2013/ Accepted: 26 May 2013/Published online: 13 June 2013

(C) The Author(s) 2013. This article is published with open access at Springerlink.com

\begin{abstract}
Purpose It is advantageous to individualize high-dose methotrexate (HDMTX) to maintain adequate exposure while minimizing toxicities. Previously, we accomplished this through within-course dose adjustments.

Methods In this study, we evaluated a strategy to individualize HDMTX based on clearance of each individual's previous course of HDMTX in 485 patients with newly diagnosed acute lymphoblastic leukemia. Doses were individualized to achieve a steady-state plasma concentration (Cpss) of 33 or $65 \mu \mathrm{M}$ (approximately 2.5 or $5 \mathrm{~g} / \mathrm{m}^{2} /$ day) for low- and standard-/high-risk patients, respectively.
\end{abstract}

Electronic supplementary material The online version of this article (doi:10.1007/s00280-013-2206-x) contains supplementary material, which is available to authorized users.

J. L. Pauley - J. C. Panetta - K. R. Crews - J. McCormick ·

W. E. Evans · M. V. Relling $(\bowtie)$

Department of Pharmaceutical Sciences, St. Jude Children's

Research Hospital, 262 Danny Thomas Place, Memphis,

TN 38105-3678, USA

e-mail: mary.relling@stjude.org

J. C. Panetta - K. R. Crews - S. C. Howard - J. T. Sandlund .

S. Jeha - R. Ribeiro · J. Rubnitz - C.-H. Pui ·

W. E. Evans - M. V. Relling

Colleges of Medicine and Pharmacy, University of Tennessee,

Memphis, TN, USA

D. Pei - C. Cheng

Department of Biostatistics, St. Jude Children's Research

Hospital, 262 Danny Thomas Place, Memphis, TN 38105-3678,

USA

S. C. Howard - J. T. Sandlund - S. Jeha $\cdot$ R. Ribeiro •

J. Rubnitz - C.-H. Pui

Department of Oncology, St. Jude Children's Research Hospital,

262 Danny Thomas Place, Memphis, TN 38105-3678, USA
Results Individualized doses resulted in 70 and $63 \%$ of courses being within $20 \%$ of the targeted Cpss in the lowand standard-/high-risk arms, respectively, compared to $60 \%(p<0.001)$ and $61 \%(p=0.43)$ with conventionally dosed therapy. Only $1.3 \%$ of the individualized courses in the standard-/high-risk arm had a Cpss greater than $50 \%$ above the target compared to $7.3 \%(p<0.001)$ in conventionally dosed therapy. We observed a low rate ( $8.5 \%$ of courses) of grade 3-4 toxicities. The odds of gastrointestinal toxicity were related to methotrexate plasma concentrations in both the low $(p=0.021)$ - and standard-/high-risk groups $(p=0.003)$.

Conclusions Individualizing HDMTX based on the clearance from the prior course resulted in fewer extreme Cpss values and less delayed excretion compared to conventional dosing.

Keywords Methotrexate - Acute lymphoblastic leukemia . Pharmacokinetics $\cdot$ Individualized therapy

\section{Introduction}

Improvements in cure rates for childhood acute lymphoblastic leukemia (ALL) are due partly to the use of riskdirected chemotherapy [1-5]. One important element of chemotherapy is high-dose methotrexate (HDMTX) (doses $\geq 1 \mathrm{~g} / \mathrm{m}^{2}$ ) with leucovorin rescue [3, 6-9]. High doses of methotrexate $\left(5 \mathrm{~g} / \mathrm{m}^{2}\right)$ improve the outcome of patients with T-lineage ALL, consistent with the fact that T-lineage blasts accumulate less methotrexate polyglutamates than blasts of B-lineage ALL, thereby requiring higher serum concentrations to achieve the same cytotoxic effect $[6,10$ 12]. In addition, methotrexate dosages higher than $1 \mathrm{~g} / \mathrm{m}^{2}$ are beneficial for patients with B-lineage ALL [13-16]. 
However, HDMTX has been associated with potentially severe toxicities, [17-20] although the introduction of pretreatment prehydration, urinary alkalinization, routine monitoring of serum methotrexate concentrations, and the incorporation of leucovorin rescue has decreased their incidence [21-25]. High plasma methotrexate concentrations are also associated with increased toxicity which may delay subsequent courses of chemotherapy [22, 26, 27]. Therefore, it is desirable to maintain plasma concentrations within the putative cytotoxic range for leukemic blasts [28] and below those associated with significant toxicity. We previously conducted a prospective randomized trial in children with ALL which demonstrated that when HDMTX doses were adjusted during the 24-h drug infusion to achieve desired plasma exposure levels, relapse rates were lower compared to conventional fixed doses of methotrexate based on body surface area [13]. Another study in patients with relapsed ALL showed that individualizing doses decreased inter-patient variability and avoided potentially toxic methotrexate concentrations [29].

However, adjusting doses of HDMTX during an infusion requires extremely fast turn-around time for analysis of plasma methotrexate concentrations, estimating pharmacokinetic parameters, and implementing adjusted doses. Therefore, the objectives of this follow-up study were to evaluate the feasibility of an approach that individualized HDMTX dosage based on the pharmacokinetics of each individual patient's previous course of methotrexate, with 14 or more days between each course and to assess the acute toxicities associated with HDMTX.

\section{Patients and methods}

Between June 2000 and October 2007, 501 patients were enrolled on St. Jude Total Therapy Study XV for ALL [1]. Three patients were subsequently excluded based on a revised diagnosis of myeloid leukemia, and two patients did not receive HDMTX during consolidation therapy. In addition, for this analysis, 12 patients with Down syndrome were excluded because they received lower doses of methotrexate $\left(500 \mathrm{mg} / \mathrm{m}^{2}\right)$ that were not individualized based on pharmacokinetics. During this front-line study of childhood ALL, patients were randomly assigned to receive initial treatment (window) with HDMTX $\left(1 \mathrm{~g} / \mathrm{m}^{2}\right)$ over a period of 4 or $24 \mathrm{~h}$ [30]. Four days later, remissioninduction therapy was begun with prednisone, vincristine, daunorubicin, asparaginase, cyclophosphamide, mercaptopurine and cytarabine. Risk classification was based on presenting characteristics and treatment response to remission-induction therapy, and patients were assigned to the low-, standard- or high-risk categories [1]. Central nervous system-directed therapy with triple intrathecal therapy was given based on the patient's central nervous system status [1].

The 6-week induction period was followed by consolidation, consisting of four courses of HDMTX given every other week together with triple intrathecal therapy with methotrexate, hydrocortisone and cytarabine on the day of HDMTX and daily oral mercaptopurine at $50 \mathrm{mg} / \mathrm{m}^{2} /$ day at bedtime for the 8 weeks of consolidation. Serum chemistries were required to be within normal limits prior to receipt of HDMTX. Methotrexate doses were individualized using the pharmacokinetic parameters estimated from the individual's previous course of HDMTX. If the patient had not received HDMTX as part of window therapy, then their first course of HDMTX in consolidation was a fixed dose of $2.5 \mathrm{mg} / \mathrm{m}^{2}$ (low-risk arm) or $5 \mathrm{mg} / \mathrm{m}^{2}$ (standard-/ high-risk arm) infused over $24 \mathrm{~h}$. Patients on the low-risk treatment arm had doses individualized to achieve a steadystate plasma concentration (Cpss) of $33 \mu \mathrm{M}$ (the average Cpss expected for patients receiving $2.5 \mathrm{~g} / \mathrm{m}^{2} / 24 \mathrm{~h}$ based on extensive prior pharmacokinetic estimates in children with ALL) [13]. Those on the standard-/high-risk arm were individualized to a Cpss of $65 \mu \mathrm{M}$ (the average Cpss expected for patients receiving $5 \mathrm{~g} / \mathrm{m}^{2} / 24 \mathrm{~h}$, based on prior pharmacokinetic estimates) [13]. Patients received prehydration containing sodium bicarbonate starting the evening prior (at 100 or $125 \mathrm{~mL} / \mathrm{m}^{2} / \mathrm{h}$ for low risk or standard/high risk, respectively). In some cases, prehydration was administered for a minimum of $2 \mathrm{~h}$ prior at $200 \mathrm{~mL} / \mathrm{m}^{2} / \mathrm{h}$ with a sodium bicarbonate bolus. This occurred in extenuating circumstances such as when patients were not able to arrive in our clinic the evening prior to treatment. The HDMTX was not started until the urine $\mathrm{pH}$ was $\geq 6.5$. Intravenous fluids continued until at least $42 \mathrm{~h}$ after the start of methotrexate. HDMTX was given as a $10 \%$ loading dose over $1 \mathrm{~h}$, with the remaining $90 \%$ administered over $23 \mathrm{~h}$. Urine $\mathrm{pH}$ was monitored with each void, and an IV sodium bicarbonate bolus was given if the urine $\mathrm{pH}$ was $\leq 6$ [22].

All patients had methotrexate concentrations measured by fluorescence polarization immunoassay (TDx/TDxFLx Systems, Abbot Laboratories, Abbot Park, IL, USA) prior to the dose and at 6,23 and $42 \mathrm{~h}$ from the infusion start. The lower limit of quantification of the assay was $0.03 \mu \mathrm{M}$.

Leucovorin dosing

Leucovorin rescue was started at $42 \mathrm{~h}$ from the beginning of the HDMTX infusion (Supplemental Table 1). Those on the low-risk arm received $10 \mathrm{mg} / \mathrm{m}^{2}$ of leucovorin every $6 \mathrm{~h}$ for 5 doses and those on the standard-/high-risk arm received $15 \mathrm{mg} / \mathrm{m}^{2}$ of leucovorin every $6 \mathrm{~h}$ for 5 doses. Leucovorin doses were increased for patients with delayed excretion of methotrexate, defined as methotrexate 
concentrations $>1 \mu \mathrm{M}$ at $42 \mathrm{~h}$ (Supplemental Table 1). For those with delayed excretion, plasma methotrexate concentrations were monitored, and leucovorin was continued until plasma methotrexate concentrations were $<0.1 \mu \mathrm{M}$. Patients with changes to their clinical status (e.g., an increase in serum creatinine; early mucositis; evidence of pleural effusions or ascites; significantly delayed methotrexate excretion) were followed until they achieved an undetectable plasma methotrexate concentration $(<0.03 \mu \mathrm{M})$.

\section{Pharmacokinetic modeling}

Methotrexate pharmacokinetic parameters were estimated by fitting a two-compartment model [13, 31-33] to each individual's data set using the a posteriori probability estimation method implemented in ADAPT II [34]. Extensive prior studies established the prior distribution of the methotrexate pharmacokinetic parameters and allowed the implementation of our Bayesian approach using relatively sparse sampling (3-4 samples per course) in this and our prior studies [13]. The prior pharmacokinetic parameters (mean $\pm \mathrm{SD})$ were as follows: $k_{\mathrm{e}}(0.70 \pm 0.221 / \mathrm{h})$; $V\left(9.03 \pm 4.70 \mathrm{~L} / \mathrm{m}^{2}\right) ; k_{\mathrm{cp}}(0.080 \pm 0.0501 / \mathrm{h}) ;$ and $k_{\mathrm{pc}}$ $(0.11 \pm 0.00381 / \mathrm{h})$. Clearance (CL) was calculated as $k_{\mathrm{e}} \cdot V$. Note that volume and clearance were always normalized for body surface area.

\section{Methotrexate dose individualization}

The individualized methotrexate dose for each course was determined as follows (Supplemental Figure 1):

$$
\begin{aligned}
& \text { Targeted dose }\left(\mathrm{mg} / \mathrm{m}^{2}\right) \\
& =\text { Infusion Length }(\mathrm{h}) \cdot \text { Predicted CL }\left(\mathrm{L} / \mathrm{h} / \mathrm{m}^{2}\right) \\
& \quad \cdot \text { Cpss }(\mu \mathrm{M}) /(2.2 \cdot(1-\text { fraction loading dose }))
\end{aligned}
$$

where the infusion length was $23 \mathrm{~h}(24-1 \mathrm{~h}$ loading dose infusion), the fraction loading dose was 0.1 (or $10 \%$ ), and the predicted clearance was defined as follows. For the low-risk arm, the predicted clearance was assumed to be equal to the clearance of the previous course of methotrexate. For the first 53 patients in the standard-/high-risk arms, the predicted clearance was also assumed to be equal to the clearance of the previous course of HDMTX. However, due to the lower success of individualization by this approach for patients on the standard-/high-risk arm (see "Results"), we investigated whether serum chemistries (obtained within $24 \mathrm{~h}$ before the targeted course) or patient demographics could help improve our ability to predict the MTX clearance in the patients on the standard-/ high-risk arm and thus more accurately target individuals. We considered serum chemistries as possible predictors of
MTX clearance because when MTX is infused over $24 \mathrm{~h}$, both renal and hepatic function play a role in clearance. Approximately $40 \%$ of HDMTX is cleared non-renally, mostly via hepatic metabolism to 7-hydroxymethotrexate [35], and both SGPT [36] and serum bilirubin [22] have been associated with MTX clearance. Therefore, using the data from the initial group of standard-/high-risk patients on the protocol, we built a linear model with the previous course MTX clearance, serum chemistries and demographics as potential predictors of the current course MTX clearance, using stepwise linear regression (forward selection followed by backward elimination) [37]. We found a significant association between methotrexate clearance and serum concentrations of creatinine, bilirubin and SGPT (Supplemental Figure 2), and we estimated the predicted clearance for patients in the standard-/high-risk arms based on a linear function of the clearance of the previous course of methotrexate along with current serum concentrations of creatinine, bilirubin and SGPT (Supplemental Figure 1). If the clearance for the previous course of methotrexate was $>125 \mathrm{~mL} / \mathrm{min} / \mathrm{m}^{2}$, we used only the previous clearance as the predicted clearance because it was a more accurate predictor than the combination of prior clearance and serum creatinine, bilirubin and SGPT concentrations in such cases (Supplemental Figure 1). Among patients on the low-risk arm, simulations did not demonstrate an improvement in the prediction of clearance if serum chemistries were incorporated.

We also simulated the methotrexate exposure (Cpss and $42 \mathrm{~h}$ methotrexate concentration) that would have been achieved had patients received the conventional dose (i.e., $2.5 \mathrm{~g} / \mathrm{m}^{2}$ for low risk and $5 \mathrm{~g} / \mathrm{m}^{2}$ for standard/high risk), using the estimated methotrexate pharmacokinetic parameters for each course in each individual.

\section{Targeting success}

We measured targeting success by comparing the proportion of courses that were successfully targeted (defined by $\pm 20 \%$ of the target Cpss [33 $\mu \mathrm{M}$ for low risk and $65 \mu \mathrm{M}$ for standard/high risk]) by pharmacokinetically based doses vs fixed doses (simulated at 2.5 or $5.0 \mathrm{~g} / \mathrm{m}^{2}$ for low or standard/high risk, respectively) using the McNemar's $X^{2}$ test. This $\pm 20 \%$ window was based on our prior intracourse targeting study [13]. In addition, all targeted patients had their doses adjusted to attempt to achieve the target concentration, even if their predicted Cpss was within $20 \%$ of the target Cpss.

\section{Toxicities}

Toxicities during HDMTX consolidation were graded using the NCI Common Toxicity Criteria version 2.0 
(http://ctep.cancer.gov/protocolDevelopment/electronic_ applications/ctc.htm); we recorded any grade 3-4 toxicities in the following categories: allergy/immunology, cardiovascular, constitutional symptoms, dermatology/skin, gastrointestinal, hepatic, infection/febrile neutropenia, metabolic/laboratory, musculoskeletal, neurology, pain, pulmonary, renal/genitourinary. We determined whether methotrexate exposure (Cpss or $42 \mathrm{~h}$ concentration), delayed methotrexate excretion ( $42 \mathrm{~h}$ methotrexate concentration $>1 \mu \mathrm{M}$ ), leucovorin dose, or success of targeting methotrexate was associated with the incidence of grade 3 or greater toxicity using a univariate generalized estimating equation (GEE) model.

\section{Results}

Low-risk arm individualization

Of the 915 consolidation HDMTX courses delivered to the 233 patients on the low-risk arm, 754 courses in 220 patients were individualized based on the methotrexate clearance from the previous course. The patient demographics are described in Supplemental Table 2. The remaining doses were not pharmacokinetically based due to various reasons, including no previous clearance data being available, doses being lowered due to prior toxicities, or other clinical issues such as unstable renal function. The median dose administered for these pharmacokinetically based courses was $2.8 \mathrm{~g} / \mathrm{m}^{2}$, with a range of $0.9-5.3 \mathrm{~g} / \mathrm{m}^{2}$, and the median Cpss for the pharmacokinetically based courses was $33 \mu \mathrm{M}$ with a range from 15.6 to $92.3 \mu \mathrm{M}$. This median Cpss observed with pharmacokinetically based doses was $10 \%$ higher than the simulated median Cpss for patients on this study given a fixed dose of $2.5 \mathrm{~g} / \mathrm{m}^{2} \quad(p<0.001)$. Figure 1 shows the methotrexate clearance subdivided by course. The overall population clearance, inter-individual (IIV) and inter-occasion (IOV) variability of the clearance were $117.9 \mathrm{ml} / \mathrm{min} / \mathrm{m}^{2}, 17.7$ and $15.7 \%$, respectively.

For the low-risk arm, a higher proportion (69.5\%) of pharmacokinetically based courses were within target (defined as $\pm 20 \%$ of the Cpss of $33 \mu \mathrm{M}$ ) compared to that estimated $(60.3 \%)$ had patients received a fixed dose of $2.5 \mathrm{~g} / \mathrm{m}^{2}$ ( $p<2 \times 10^{-4}$; Fig. 2).

There was substantial IIV and IOV in methotrexate clearance for both window and consolidation therapy. When subdivided by course, the IOV during the window and first two consolidation courses was higher than that for the later consolidation courses ( 15.8 vs. $11.3 \% ; p<0.03)$. When comparing the change in clearance ([previous clearance-current clearance]/current clearance) for pharmacokinetically based courses 1 and 2 vs courses 3 and 4,
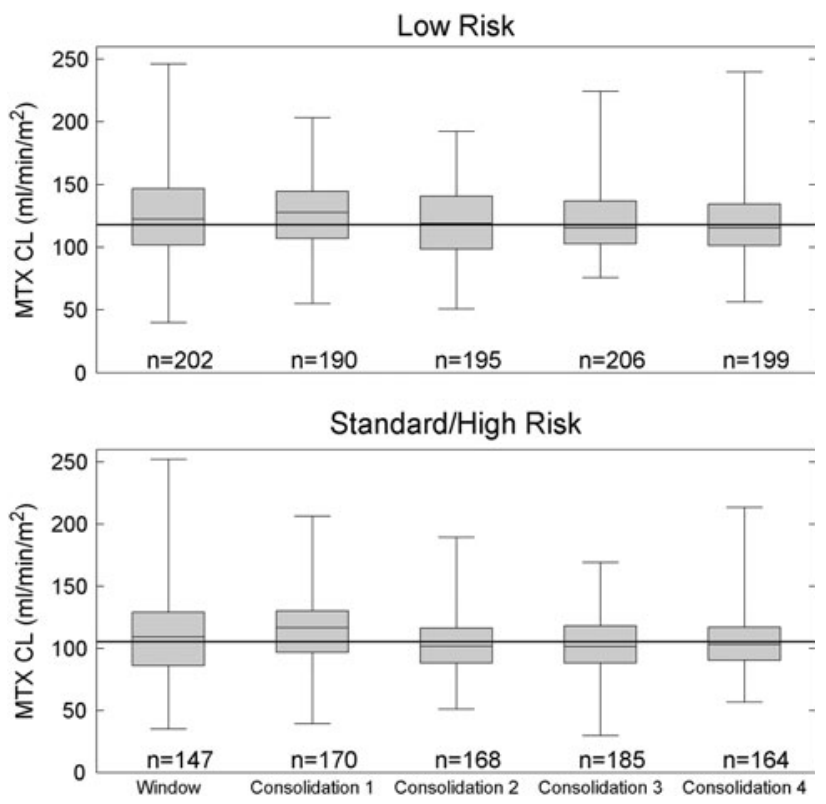

Fig. 1 Methotrexate clearance, MTX CL $\left(\mathrm{ml} / \mathrm{min} / \mathrm{m}^{2}\right)$, by course and risk arm. The horizontal line in each box represents the median, the shaded boxes represent the quartiles, and the whiskers represent the range observed in patients for each course. The solid horizontal line across all courses represents the population clearance for all courses

we observed more variability in the change in clearance for the first two courses compared to the last two courses ([-23, $34 \%]$ and [-20, 28\%] (10th, 90th percentile), respectively; $p<0.03$ ). These differences in IOV over time made it more difficult to accurately target courses 1 and 2 than the latter two consolidation courses. We observed a higher proportion of courses with Cpss within the target range for individualized doses in the latter two consolidation courses: for consolidation 3 and 4: 9.6, 74.6, and $15.8 \%$ of courses were below target, within target and above target, respectively; vs for consolidation 1 and 2: $15.5,63.6$, and $20.9 \%$ of courses were below, within and above target, respectively ( $p<0.001)$.

To assess whether individualizing doses minimized the proportion of courses with extremes of plasma concentrations of methotrexate, we compared the percent of courses that yielded Cpss that were outside $\pm 50 \%$ of the target (i.e., Cpss $<16.5 \mu \mathrm{M}$ or $>49.5 \mu \mathrm{M}$ for patients on the lowrisk arm, Fig. 2) for individualized courses vs that simulated with conventional fixed dosing. Due to the higher than expected clearance in patients in this arm, our simulations show that the $2.5 \mathrm{~g} / \mathrm{m}^{2}$ fixed dose actually would have resulted in fewer courses with Cpss above $49.5 \mu \mathrm{M}$ compared to individualized doses (1.6 vs. $3.8 \%$; $p<0.005)$, while there was no difference in courses with Cpss below $16.5 \mu \mathrm{M}$ (0.5 vs. $0.3 \% ; p>0.1)$.

Finally, we observed a lower proportion of pharmacokinetically based courses with delayed excretion compared to 


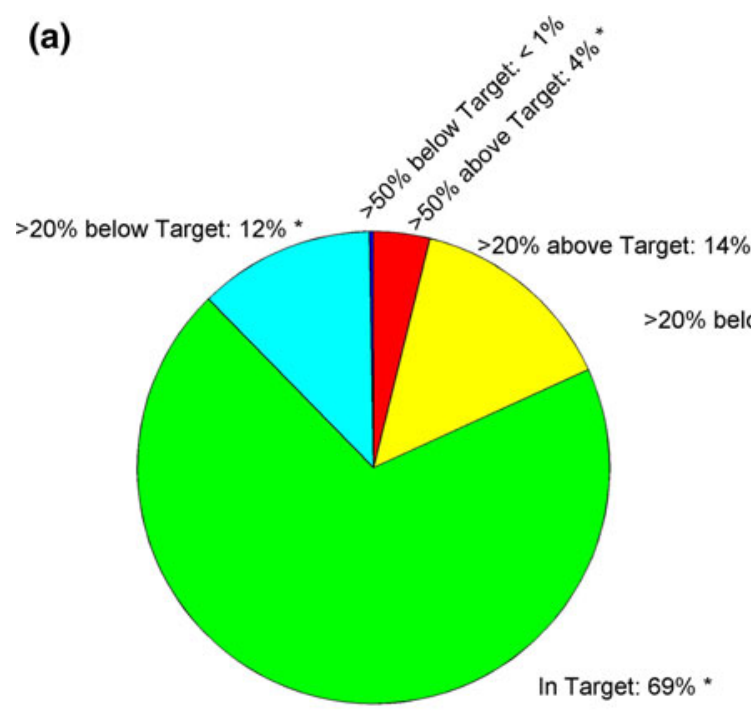

Individualized Therapy

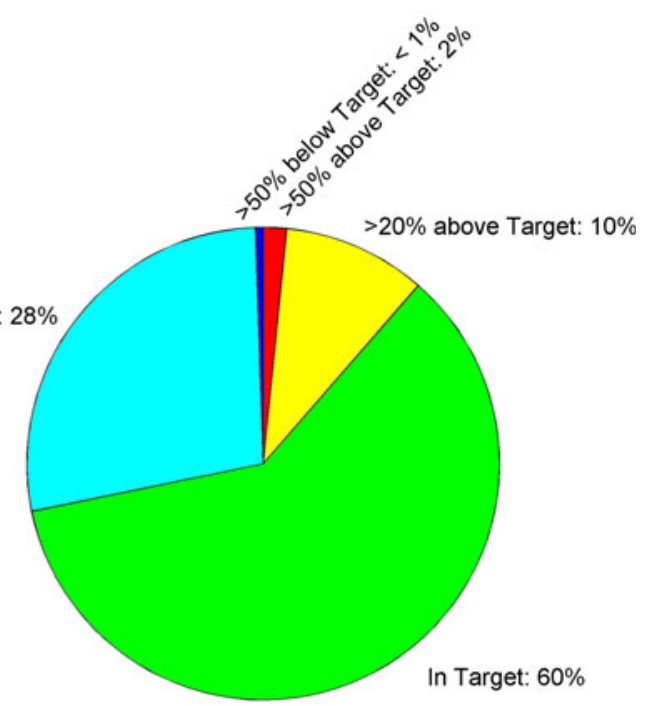

Simulated Fixed Dose Therapy

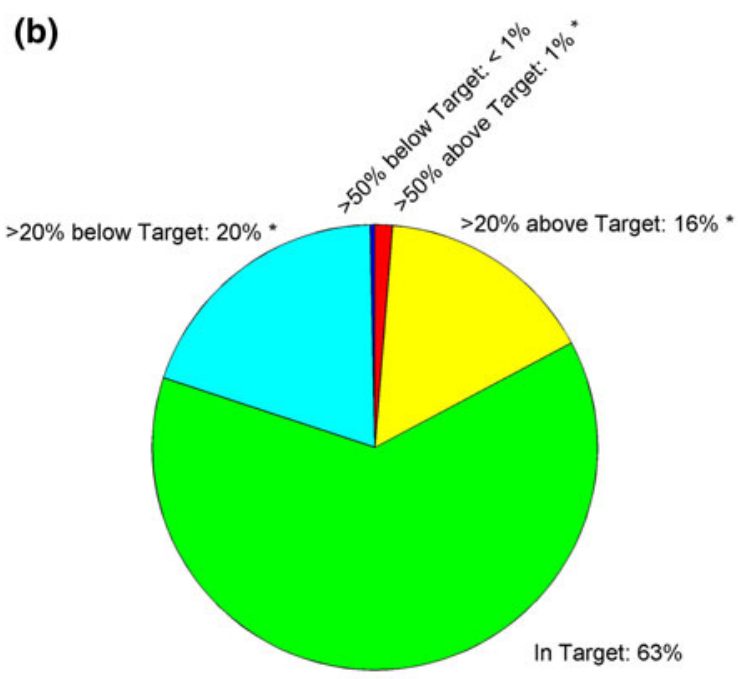

Individualized Therapy

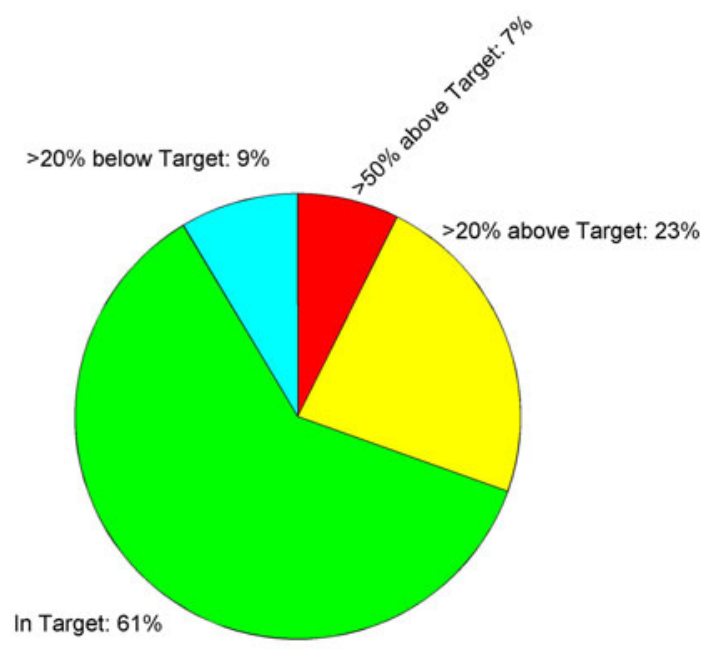

Simulated Fixed Dose Therapy

Fig. 2 Percentage of courses based on achieved MTX plasma steadystate concentrations (Cpss) (individualized therapy) compared to the percentage predicted based on conventional dosing (simulated for fixed doses). The groups are defined as follows: Dark Blue Cpss greater than $50 \%$ below target Cpss, Light Blue Cpss between 20 and $50 \%$ below target, Green Cpss within $\pm 20 \%$ of the target, Yellow

simulated fixed dose courses (7.4 vs. $8.9 \%$, respectively, $p<0.04)$.

Standard-/high-risk arm individualization

Of the 965 courses of consolidation HDMTX delivered to 252 patients on the standard-/high-risk arm, 97 courses in 53 patients had doses individualized based on the clearance from the previous course; subsequently, for 627 courses in

Cpss between 20 and $50 \%$ above target, Red Cpss greater than $50 \%$ above target. *Significance $(p<0.001)$ in the difference in the proportion of courses between individualized therapy relative to simulated fixed dose therapy (otherwise $p>0.1$ ). a Low-risk arm: target concentration: $33 \mu \mathrm{M}$. b Standard-/high-risk arm: target concentration: $65 \mu \mathrm{M}$

224 patients, doses were individualized based on the methotrexate clearance from the previous course along with current serum creatinine, bilirubin, and SGPT. The patient demographics are described in Supplemental Table 2. The remaining courses were not pharmacokinetically based due to various reasons including no previous clearance being available, doses being lowered due to toxicities, or other clinical issues, such as unstable renal function. The median dose for courses individualized using 
Table 1 Grade 3 or 4 toxicities during consolidation therapy

\begin{tabular}{lcccc}
\hline & LR individualized & LR not individualized & S/HR individualized & S/HR not individualized \\
\hline Methotrexate courses $(n)$ & 754 & 161 & 627 & 338 \\
Patients $(n)$ & 220 & 101 & 224 & 176 \\
Courses with infection/febrile neutropenia $(n)$ & 33 & 10 & 29 & 26 \\
Course with gastrointestinal toxicities $(n)$ & 13 & 3 & 19 & 22 \\
Courses with any grade 3 or 4 toxicity $[n(\%)]$ & $52(6.9)$ & $14(8.7)$ & $50(8.0)$ & $44(13.0)$ \\
\hline
\end{tabular}

$L R$ Low-risk therapy arm, $S / H R$ standard-/high-risk therapy arm, Individualized courses for which the methotrexate dose was adjusted based on the prior course's pharmacokinetic parameters, Not Individualized courses for which the methotrexate was dosed conventionally based on body size

only the previous clearance was $4.5 \mathrm{~g} / \mathrm{m}^{2}$ (range $1.5-6.7 \mathrm{~g} /$ $\mathrm{m}^{2}$ ), and for courses individualized using both the previous clearance and serum chemistries was $4.6 \mathrm{~g} / \mathrm{m}^{2}$ (range 2.9-8.6 g/ $\mathrm{m}^{2}$ ). The median [10th-90th percentile] Cpss for the courses targeted using only the previous clearance was $63 \mu \mathrm{M}[34,84 \mu \mathrm{M}]$ while that for the courses individualized, using both the previous clearance and serum chemistries was $63 \mu \mathrm{M}[46,83 \mu \mathrm{M}]$. This median Cpss observed with pharmacokinetically based doses was $10 \%$ lower than the simulated median Cpss for patients on this study given a fixed dose of $5 \mathrm{~g} / \mathrm{m}^{2} \quad(p<0.001)$. Figure 1 shows the methotrexate clearance subdivided by course. The overall population clearance, IIV, and IOV variability of the clearance were $105.2 \mathrm{ml} / \mathrm{min} / \mathrm{m}^{2}, 17.5$, and $16.9 \%$, respectively.

As in the low-risk arm, the IOV for methotrexate clearance for the window and first two consolidation courses was higher than that for the later consolidation courses (18.2 vs. $10.7 \% ; p<0.002)$. Again, the change in clearance for individualized courses 1 and 2 displayed more variability than for courses 3 and $4([-29,35 \%]$ and $[-21,24 \%]$ (10th, 90th percentile), respectively; $p<0.003)$. As with the low-risk arm, the high IOV in the clearance for early courses made it more difficult to accurately individualize the first two consolidation courses.

For the first 97 courses given to patients on the standard-/high-risk arm, when methotrexate was dosed based only on the prior clearance, there was a trend for a lower proportion of courses to achieve Cpss in the target range compared to a conventional dose of $5 \mathrm{~g} / \mathrm{m}^{2}$ (42.3 vs. $55.7 \% ; p=0.087)$ and also compared to the subsequent 627 courses, when methotrexate was dosed based on the previous clearance plus the current serum chemistries (42.3 vs. $62.8 \%, p<0.001)$. Thus, our final approach was to base doses for the standard-/high-risk group on both the previous clearance and the current serum chemistries. In the final analysis, there was not a significant difference in the proportion of pharmacokinetically based courses with Cpss that were within target $(n=627)$ compared to that of conventional dosing of $5 \mathrm{~g} / \mathrm{m}^{2}$ (62.8 vs. $60.9 \%$, respectively; $p=0.43$; Fig. 2). However, there was a significantly lower proportion of courses with Cpss above the targeted range with individualized dosing compared to that predicted with conventional dosing (17.2 vs. $30.5 \%$, respectively; $p<0.001$; Fig. 2). Again, due to the larger IOV in methotrexate PK for the early compared to later courses, we observed a trend toward $(p=0.12)$ better success in achieving target Cpss with individualized doses in the latter two consolidation courses (consolidation 3 and 4: 17.8, 65.0, and $17.2 \%$ below, within and above target, respectively) compared to consolidation 1 and 2 (22.7, 60.1, and $17.3 \%$ below, within and above target, respectively).

Next, to assess how well the individualization avoided extreme plasma concentrations of MTX, we compared how many courses yielded Cpss outside $\pm 50 \%$ of the target (i.e., Cpss $<32.5$ or $>97.5 \mu \mathrm{M}$ ). By using pharmacokinetically based doses, the proportion of courses with extremely high Cpss was lower than that simulated with a fixed dose (1.3 vs. $7.3 \% ; p<10^{-8}$, Fig. 2 ), while there was no difference in the frequency of courses with extremely low Cpss ( 0.3 vs $0.0 \% ; p=0.48$, Fig. 2).

Finally, we observed a lower proportion of courses with delayed excretion when individualized dosing was used compared to what we would have observed had we given fixed doses (14.7 vs. $19.8 \%$, respectively, $p<0.001)$.

\section{Toxicity}

The overall rate of any grade 3-4 toxicity in this study was low (160 events from 1,880 methotrexate consolidation courses or $8.5 \%$ of courses) (Table 1). Infection/febrile neutropenia and gastrointestinal toxicities were the most common events, occurring in 5.2 and $3.0 \%$ of courses, respectively. As expected based on the protocol guidelines (Supplemental Table 1), there was a 4.3-fold increase in the total leucovorin dose in patients with delayed excretion for the low-risk arm $(p<0.001)$ and a 2.2-fold increase for the standard- and high-risk arms $(p<0.001)$.

We investigated the relationship between methotrexate Cpss, methotrexate 42-h concentration, targeting success (Cpss $\pm 20 \%$ of target), leucovorin dose, methotrexate 
delayed excretion, and risk of gastrointestinal toxicity. In the low-risk arm, higher methotrexate Cpss corresponded to a higher odds ( $5 \%$ higher for every $1 \mu \mathrm{M}$ increase in the Cpss) of having a grade 3 or greater gastrointestinal toxicity (OR 1.05; $95 \%$ CI 1.01-1.09, $p=0.021$ ) (Supplemental Table 3). In the standard-/high-risk arm, methotrexate delayed excretion was associated with gastrointestinal toxicities (OR 3.02; $95 \%$ CI 1.45-6.32, $p=0.003$ ). No other measures of methotrexate exposure or targeting success related significantly to toxicity ( $p>0.05$ in all cases).

Of a total of 1,880 consolidation courses in 484 patients receiving HDMTX, severe delayed excretion (requiring glucarpidase) occurred for a single course in each of only 4 patients $(0.8 \%$ of patients and $0.21 \%$ of courses). All 4 of these patients received targeted dosing on the standard-/ high-risk arm and had a large (24-71\%) decrease in their MTX clearance between their previous course of MTX (used for targeting) and the course with severe delayed excretion. Patients requiring glucarpidase were eligible to be targeted with future courses. MTX concentrations used to target were obtained prior to administration of glucarpidase; therefore, falsely elevated concentrations due to the glucarpidase were not an issue.

\section{Discussion}

HDMTX is an important chemotherapeutic agent that contributes to the high cure rate of pediatric ALL $[6,7,38]$. Higher plasma methotrexate concentrations following HDMTX have been associated with a lower risk of relapse $[10,11]$; however, high concentrations may lead to delayed excretion, increased toxicity and delays in receiving subsequent courses of chemotherapy [22]. In a previous study, we have shown that adjusting the dose of methotrexate during the 24-h infusion, to account for inter-individual differences in drug clearance and to achieve a target Cpss, improved the outcome in children with B-lineage leukemia $[10,13,29]$. Other studies have retrospectively investigated therapeutic drug-monitoring approaches to predict MTX concentrations after a dose to help determine appropriate leucovorin rescue [31]. In the current study, we tested whether we could successfully individualize doses of HDMTX based on clearance estimates from the prior course of MTX for each child; this method relies on the assumption that IOV is low enough that prior clearance accurately reflects current clearance. However, we observed high IOV, particularly for the first and second course of HDMTX. Recognizing this large IOV, we modified our targeting strategy in the standard-/high-risk arm to include not only prior pharmacokinetic parameters, but also serum chemistries (drawn within $24 \mathrm{~h}$ of each planned
HDMTX course) as a surrogate for changing methotrexate clearance. Simulations showed that serum chemistries would not have improved targeting in the low-risk arm.

Targeting doses based on the prior course's pharmacokinetic parameters was moderately successful. For the lowrisk arm, more courses had Cpss that were within target (70 \%) compared to simulated conventional dosing (60\%; $p<0.001)$. The median targeted dose was $11 \%$ higher than the conventional $2.5 \mathrm{~g} / \mathrm{m}^{2}$ dose without an increase in delayed excretion. For the standard-/high-risk arm, even after incorporation of current serum chemistries, we were not successful in improving the percentage of courses with Cpss in the target range $( \pm 20 \%)$ over that achieved with conventional dosing. We attribute this finding to the higher IOV in clearance relative to the low-risk arm, which could be exacerbated in patients on the standard-/high-risk arm because clearance of higher doses of MTX is more susceptible to transient insults (e.g., changes in hydration, drug interactions). Nonetheless, individualized dosing decreased the frequency of both extreme Cpss and of delayed excretion in patients on the standard-/high-risk arm. For courses given to patients on the standard-/highrisk arm, only $1 \%$ of those that received individualized dosing had Cpss $>50 \%$ above target compared to $7 \%$ of courses with simulated conventional dosing $(p<0.001)$. This translated into a lower proportion of individualized courses with delayed excretion.

Gastrointestinal toxicities are known side effects of HDMTX. In our prior study comparing conventional versus individualized chemotherapy, with a Cpss of only $20 \mu \mathrm{M}$, there was no difference in toxicity between the two groups [13]. In the current study, using much higher target concentrations of 33 and $65 \mu \mathrm{M}$, minimal toxicity was noted following HDMTX. Overall, $5.2 \%$ of courses were followed by grade 3-4 infection/febrile neutropenia and $3.0 \%$ was followed by grade 3-4 gastrointestinal toxicities. These toxicity rates were low compared to other studies. In the POG9404 study, patients that received HDMTX $\left(5 \mathrm{~g} / \mathrm{m}^{2}\right.$ over $\left.24 \mathrm{~h}\right)$ had a $17.8 \%$ incidence of mucositis and $66.2 \%$ incidence of infection [7]. For patients on the LAL-SHOP 99 and 2005 protocols receiving HDMTX of 3 or $5 \mathrm{~g} / \mathrm{m}^{2}$, there was an $11 \%$ incidence of mucositis [39]. D'Angelo and colleagues [40] reviewed patients enrolled on AIEOP-ALL studies 91, 95 and 00 and reported that $68.2 \%$ of patients developed grade 3-4 hematologic and non-hematologic toxicity combined after HDMTX doses of 2 or $5 \mathrm{~g} / \mathrm{m}^{2}$. The BFM study NHLBFM95 reported incidences of $36 \%$ for grade 3 and $43 \%$ for grade 4 mucositis in patients with B-cell neoplasms receiving $5 \mathrm{~g} / \mathrm{m}^{2}$ over $24 \mathrm{~h}$; perhaps this high frequency is partly attributed to only three doses of leucovorin being administered after HDMTX compared to our 5 doses [41]. Leucovorin dose was not a risk factor for toxicity in either 
our LR or S/HR arms, despite being significantly higher in those with elevated 42-h concentrations. Thus, our data suggest that the algorithms we used (Supplemental Table 1) for adjusting leucovorin doses based on plasma methotrexate concentrations, combined with our targeting strategy, were effective in producing a low frequency of adverse effects. It should also be noted that the relapse rate on the Total XV protocol was very low [1].

Renal excretion plays a major role in methotrexate elimination, and methotrexate itself can cause acute nephrotoxicity. Close monitoring of patients receiving methotrexate is imperative. At St. Jude, close monitoring of fluid status, urine output, urine $\mathrm{pH}$, laboratory values, methotrexate concentrations [22, 23, 42] and drug interactions (through review of the patient's electronic record) in order to prevent delayed excretion and toxicity are performed with each course of HDMTX. Close monitoring allows early intervention (e.g., increasing fluid hydration, discontinuing interacting drugs) and potentially reduces adverse effects. Using prior information about a patient's MTX clearance to individualize a patient's dosage of HDMTX is an added way to potentially reduce adverse effects when within-course dose adjustment is not feasible. However, we acknowledge that targeting doses based on clearance did not prevent all cases of severe nephrotoxicity. For those patients who do experience nephrotoxicity during or after a course of HDMTX, it is likely that intracourse clearance estimates with intra-course dose adjustments, as we previously described [13], would be more likely to prevent recurrence of severe nephrotoxicity than between-course adjustments.

Our current clinical approach to administering HDMTX in ALL is as follows. Because with the lower dose $\left(\sim 2.5 \mathrm{~g} / \mathrm{m}^{2}\right)$, the proportion of courses with delayed excretion was only modestly reduced (8.9 vs. $7.4 \%$ ) by targeting, we generally do not pharmacokinetically adjust doses of this lower dose of HDMTX unless the patient displays unstable or poor renal function. For patients receiving the equivalent of $5 \mathrm{~g} / \mathrm{m}^{2}$, we adjust doses based on the pharmacokinetics of the prior course in most patients, because in the current study, we showed that individualizing doses reduced both the frequency of extremely high Cpss (1.3 vs. $7.3 \%)$ and the frequency of delayed excretion (14.7 vs. $19.8 \%$ ). In the relatively rare patients with unstable clearance or renal function, we measure plasma concentrations early during the infusion as we described previously [13, 29] and adjust doses during the infusion to achieve the desired Cpss.

Acknowledgments We thank Dr. W. Paul Bowman and colleagues at Cook Children's Medical Center, Fort Worth, TX for participation in Total XV. This work was supported by grants CA21765, CA60419, CA51001, CA78224, CA36401, U01 GM92666 from the National
Institutes of Health and the American Lebanese Syrian Associated Charities.

Conflict of interest The authors declare no competing financial interests.

Open Access This article is distributed under the terms of the Creative Commons Attribution License which permits any use, distribution, and reproduction in any medium, provided the original author(s) and the source are credited.

\section{References}

1. Pui CH, Campana D, Pei D, Bowman WP, Sandlund JT, Kaste SC, Ribeiro RC, Rubnitz JE, Raimondi SC, Onciu M, CoustanSmith E, Kun LE, Jeha S, Cheng C, Howard SC, Simmons V, Bayles A, Metzger ML, Boyett JM, Leung W, Handgretinger R, Downing JR, Evans WE, Relling MV (2009) Treating childhood acute lymphoblastic leukemia without cranial irradiation. N Engl J Med 360:2730-2741

2. Pui CH, Pei D, Sandlund JT, Ribeiro RC, Rubnitz JE, Raimondi SC, Onciu M, Campana D, Kun LE, Jeha S, Cheng C, Howard SC, Metzger ML, Bhojwani D, Downing JR, Evans WE, Relling MV (2010) Long-term results of St Jude Total Therapy Studies $11,12,13 \mathrm{~A}, 13 \mathrm{~B}$, and 14 for childhood acute lymphoblastic leukemia. Leukemia 24:371-382

3. Conter V, Arico M, Basso G, Biondi A, Barisone E, Messina C, Parasole R, De Rossi G, Locatelli F, Pession A, Santoro N, Micalizzi C, Citterio M, Rizzari C, Silvestri D, Rondelli R, Lo Nigro L, Ziino O, Testi AM, Masera G, Valsecchi MG (2010) Longterm results of the Italian Association of Pediatric Hematology and Oncology (AIEOP) Studies 82, 87, 88, 91 and 95 for childhood acute lymphoblastic leukemia. Leukemia 24:255-264

4. Moricke A, Zimmermann M, Reiter A, Henze G, Schrauder A, Gadner H, Ludwig WD, Ritter J, Harbott J, Mann G, Klingebiel T, Zintl F, Niemeyer C, Kremens B, Niggli F, Niethammer D, Welte K, Stanulla M, Odenwald E, Riehm H, Schrappe M (2010) Long-term results of five consecutive trials in childhood acute lymphoblastic leukemia performed by the ALL-BFM study group from 1981 to 2000. Leukemia 24:265-284

5. Gaynon PS, Angiolillo AL, Carroll WL, Nachman JB, Trigg ME, Sather HN, Hunger SP, Devidas M (2010) Long-term results of the children's cancer group studies for childhood acute lymphoblastic leukemia 1983-2002: a children's oncology group report. Leukemia 24:285-297

6. Reiter A, Schrappe M, Ludwig WD, Hiddemann W, Sauter S, Henze G, Zimmermann M, Lampert F, Havers W, Niethammer D et al (1994) Chemotherapy in 998 unselected childhood acute lymphoblastic leukemia patients. Results and conclusions of the multicenter trial ALL-BFM 86. Blood 84:3122-3133

7. Chauvenet AR, Martin PL, Devidas M, Linda SB, Bell BA, Kurtzberg J, Pullen J, Pettenati MJ, Carroll AJ, Shuster JJ, Camitta B (2007) Antimetabolite therapy for lesser-risk B-lineage acute lymphoblastic leukemia of childhood: a report from children's oncology group study P9201. Blood 110:1105-1111

8. Silverman LB, Gelber RD, Dalton VK, Asselin BL, Barr RD, Clavell LA, Hurwitz CA, Moghrabi A, Samson Y, Schorin MA, Arkin S, Declerck L, Cohen HJ, Sallan SE (2001) Improved outcome for children with acute lymphoblastic leukemia: results of Dana-Farber Consortium Protocol 91-01. Blood 97:1211-1218

9. Clarke M, Gaynon P, Hann I, Harrison G, Masera G, Peto R, Richards S (2003) CNS-directed therapy for childhood acute 
lymphoblastic leukemia: childhood ALL Collaborative Group overview of 43 randomized trials. J Clin Oncol 21:1798-1809

10. Galpin AJ, Schuetz JD, Masson E, Yanishevski Y, Synold TW, Barredo JC, Pui CH, Relling MV, Evans WE (1997) Differences in folylpolyglutamate synthetase and dihydrofolate reductase expression in human B-lineage versus T-lineage leukemic lymphoblasts: mechanisms for lineage differences in methotrexate polyglutamylation and cytotoxicity. Mol Pharmacol 52:155-163

11. Pui CH, Sallan S, Relling MV, Masera G, Evans WE (2001) International childhood acute lymphoblastic leukemia workshop: Sausalito, CA, 30 Nov-1 Dec 2000. Leukemia 15: 707-15

12. Asselin BL, Devidas M, Wang C, Pullen J, Borowitz MJ, Hutchison R, Lipshultz SE, Camitta BM (2011) Effectiveness of high-dose methotrexate in T-cell lymphoblastic leukemia and advanced-stage lymphoblastic lymphoma: a randomized study by the Children's Oncology Group (POG 9404). Blood 118:874-883

13. Evans WE, Relling MV, Rodman JH, Crom WR, Boyett JM, Pui CH (1998) Conventional compared with individualized chemotherapy for childhood acute lymphoblastic leukemia. N Engl J Med 338:499-505

14. Lauer SJ, Shuster JJ, Mahoney DH Jr, Winick N, Toledano S, Munoz L, Kiefer G, Pullen JD, Steuber CP, Camitta BM (2001) A comparison of early intensive methotrexate/mercaptopurine with early intensive alternating combination chemotherapy for highrisk B-precursor acute lymphoblastic leukemia: a pediatric oncology group phase III randomized trial. Leukemia 15:10381045

15. Mahoney DH Jr, Shuster JJ, Nitschke R, Lauer SJ, Steuber CP, Winick N, Camitta B (1998) Acute neurotoxicity in children with B-precursor acute lymphoid leukemia: an association with intermediate-dose intravenous methotrexate and intrathecal triple therapy-a pediatric oncology group study. J Clin Oncol $16: 1712-1722$

16. Whitehead VM, Vuchich MJ, Cooley LD, Lauer SJ, Mahoney DH, Shuster JJ, Payment C, Koch PA, Akabutu JJ, Bowen T, Kamen BA, Ravindranath Y, Emami A, Look AT, Beardsley GP, Pullen DJ, Camitta B (1998) Accumulation of methotrexate polyglutamates, ploidy and trisomies of both chromosomes 4 and 10 in lymphoblasts from children with B-progenitor cell acute lymphoblastic leukemia: a pediatric oncology group study. Leuk Lymphoma 31:507-519

17. Chan H, Evans WE, Pratt CB (1977) Recovery from toxicity associated with high-dose methotrexate: prognostic factors. Cancer Treat Rep 61:797-804

18. Von Hoff DD, Penta JS, Helman LJ, Slavik M (1977) Incidence of drug-related deaths secondary to high-dose methotrexate and citrovorum factor administration. Cancer Treat Rep $61: 745-748$

19. Widemann BC, Adamson PC (2006) Understanding and managing methotrexate nephrotoxicity. Oncologist 11:694-703

20. Gupta S, Antillon FA, Bonilla M, Fu L, Howard SC, Ribeiro RC, Sung L (2011) Treatment-related mortality in children with acute lymphoblastic leukemia in Central America. Cancer 117:47884795

21. Buchen S, Ngampolo D, Melton RG, Hasan C, Zoubek A, Henze G, Bode U, Fleischhack G (2005) Carboxypeptidase G2 rescue in patients with methotrexate intoxication and renal failure. $\mathrm{Br} \mathbf{J}$ Cancer 92:480-487

22. Relling MV, Fairclough D, Ayers D, Crom WR, Rodman JH, Pui CH, Evans WE (1994) Patient characteristics associated with high-risk methotrexate concentrations and toxicity. J Clin Oncol 12:1667-1672

23. Evans WE, Pratt CB, Taylor RH, Barker LF, Crom WR (1979) Pharmacokinetic monitoring of high-dose methotrexate. Early recognition of high-risk patients. Cancer Chemother Pharmacol 3:161-166
24. Crom WR, Evans WE (1992) Methotrexate. In: Evans WE, Schentag JJ, Jusko WJ (eds) Applied pharmacokinetics: principles of therapeutic drug monitoring. Applied Therapeutics, San Francisco, pp 1-42

25. Allegra CJ (1990) Antifolates. In: Chabner BA, Collins JM (eds) Cancer chemotherapy: principles and practice. Lippincott, Philadelphia, pp 110-153

26. Barredo JC, Synold TW, Laver J, Relling MV, Pui CH, Priest DG, Evans WE (1994) Differences in constitutive and postmethotrexate folylpolyglutamate synthetase activity in B-lineage and T-lineage leukemia. Blood 84:564-569

27. Rask C, Albertioni F, Bentzen SM, Schroeder H, Peterson C (1998) Clinical and pharmacokinetic risk factors for high-dose methotrexate-induced toxicity in children with acute lymphoblastic leukemia - a logistic regression analysis. Acta Oncol 37:277-284

28. Masson E, Relling MV, Synold TW, Liu Q, Schuetz JD, Sandlund JT, Pui CH, Evans WE (1996) Accumulation of methotrexate polyglutamates in lymphoblasts is a determinant of antileukemic effects in vivo. A rationale for high-dose methotrexate. J Clin Invest 97:73-80

29. Wall AM, Gajjar A, Link A, Mahmoud H, Pui CH, Relling MV (2000) Individualized methotrexate dosing in children with relapsed acute lymphoblastic leukemia. Leukemia 14:221-225

30. Mikkelsen TS, Sparreboom A, Cheng C, Zhou Y, Boyett JM, Raimondi SC, Panetta JC, Bowman WP, Sandlund JT, Pui CH, Relling MV, Evans WE (2011) Shortening infusion time for highdose methotrexate alters antileukemic effects: a randomized prospective clinical trial. J Clin Oncol 29:1771-1778

31. Dombrowsky E, Jayaraman B, Narayan M, Barrett JS (2011) Evaluating performance of a decision support system to improve methotrexate pharmacotherapy in children and young adults with cancer. Ther Drug Monit 33:99-107

32. Aumente D, Buelga DS, Lukas JC, Gomez P, Torres A, Garcia MJ (2006) Population pharmacokinetics of high-dose methotrexate in children with acute lymphoblastic leukaemia. Clin Pharmacokinet 45:1227-1238

33. Faltaos DW, Hulot JS, Urien S, Morel V, Kaloshi G, Fernandez C, Xuan KH, Leblond V, Lechat P (2006) Population pharmacokinetic study of methotrexate in patients with lymphoid malignancy. Cancer Chemother Pharmacol 58:626-633

34. D’Argenio D, Schumitzky A (1990) ADAPT II user's guide. Biomedical Simulations Resource, Los Angeles

35. Evans WE, Stewart CF, Hutson PR, Cairnes DA, Bowman WP, Yee GC, Crom WR (1982) Disposition of intermediate-dose methotrexate in children with acute lymphocytic leukemia. Drug Intell Clin Pharm 16:839-842

36. Crom WR, Glynn AM, Abromowitch M, Pui CH, Dodge R, Evans WE (1986) Use of the automatic interaction detector method to identify patient characteristics related to methotrexate clearance. Clin Pharmacol Ther 39:592-597

37. Draper NR, Smith H (1998) Applied regression analysis. Wiley, New York

38. Pui CH, Simone JV, Hancock ML, Evans WE, Williams DL, Bowman WP, Dahl GV, Dodge RK, Ochs J, Abromowitch M et al (1992) Impact of three methods of treatment intensification on acute lymphoblastic leukemia in children: long-term results of St Jude total therapy study X. Leukemia 6:150-157

39. Lopez-Lopez E, Martin-Guerrero I, Ballesteros J, Pinan MA, Garcia-Miguel P, Navajas A, Garcia-Orad A (2011) Polymorphisms of the SLCO1B1 gene predict methotrexate-related toxicity in childhood acute lymphoblastic leukemia. Pediatr Blood Cancer 57:612-619

40. D'Angelo V, Ramaglia M, Iannotta A, Crisci S, Indolfi P, Francese M, Affinita MC, Pecoraro G, Napolitano A, Fusco C, Oreste M, Indolfi C, Casale F (2011) Methotrexate toxicity and efficacy 
during the consolidation phase in paediatric acute lymphoblastic leukaemia and MTHFR polymorphisms as pharmacogenetic determinants. Cancer Chemother Pharmacol 68:1339-1346

41. Woessmann W, Seidemann K, Mann G, Zimmermann M, Burkhardt B, Oschlies I, Ludwig WD, Klingebiel T, Graf N, Gruhn B, Juergens H, Niggli F, Parwaresch R, Gadner H, Riehm H, Schrappe M, Reiter A (2005) The impact of the methotrexate administration schedule and dose in the treatment of children and adolescents with B-cell neoplasms: a report of the BFM group study NHL-BFM95. Blood 105:948-958

42. Stoller RG, Hande KR, Jacobs SA, Rosenberg SA, Chabner BA (1977) Use of plasma pharmacokinetics to predict and prevent methotrexate toxicity. N Engl J Med 297:630-634 